\title{
Rationalizing Inconsistent Definitions of Commodification: A Social Exchange Perspective
}

\author{
Jeffrey R. Oliver, Lindon J. Robison \\ ${ }^{1}$ Department of Sociology and Social Work, Brigham Young University-Idaho, Rexburg, USA \\ ${ }^{2}$ Department of Agricultural, Food and Resource Economics, Michigan State University, East Lansing, USA \\ Email: oliverj@byui.edu,robison@msu.edu
}

How to cite this paper: Oliver, J.R. and Robison, L.J. (2017) Rationalizing Inconsistent Definitions of Commodification: A Social Exchange Perspective. Modern Economy, 8, 1314-1327.

https://doi.org/10.4236/me.2017.811088

Received: September 22, 2017

Accepted: November 13, 2017

Published: November 16, 2017

Copyright ( 92017 by authors and Scientific Research Publishing Inc. This work is licensed under the Creative Commons Attribution International License (CC BY 4.0).

http://creativecommons.org/licenses/by/4.0/

\section{c) (i) Open Access}

\begin{abstract}
Commodification is a widely used and inconsistently defined concept. Inconsistent definitions of commodification, this paper observes, exist because alternative outcomes and consequences of converting relational goods into commodities are confused with the definition of commodification-social exchanges that convert relational goods into commodities. Distinguishing between alternative outcomes and consequences of commodification and the definition of commodification allows us to rationalize inconsistent definitions of commodification. In rationalizing inconsistent definitions of commodification, it is important to distinguish between commodities (goods valued for their ability to satisfy physical needs) and relational goods (goods valued at least in part for their connections to people which enables them to satisfy socio-emotional needs). The process of commodification is described as relocating relational goods from the humanistic sphere and relocating them in the commodity sphere.
\end{abstract}

\section{Keywords}

Commodification, Decommodification, Social Exchange, Relational Goods, Defining Commodification

\section{Introduction}

Accurate communication and scientific cooperation across the social sciences depend on consistent definitions of commonly used terms. One commonly used term which seems to be in demand is "commodification". Its usage spans disciplines and topics. Yet, it appears to be in an identity crisis because it is defined 
inconsistently. Generally speaking, commodification refers to human exchanges involving commodities. However, social scientists writing in different social science disciplines disagree about the conditions that give rise to human exchanges and the objects exchanged. As a result, they define human exchanges involving commodities inconsistently.

At the heart of commodification is social exchange theory. Homans [1] defined social exchange theory as a social activity in which tangible and intangible objects are exchanged between at least two persons. Blau [2] and Emerson [3] later noted that social exchanges may result in both social and economic outcomes.

This paper accepts the general premise of social exchange theories, that social life is a series of human exchanges. However, to resolve the inconsistent definitions of commodification, this paper distinguishes between the kinds of goods exchanged: relational goods and commodities. Distinguishing between relational goods and commodities in social exchanges allow us to rationalize inconsistencies in the five most salient definitions of commodification.

To resolve inconsistencies in the definition of commodification, the remainder of this paper is organized as follows. First, we distinguish between commodities and relational goods. Second, we review the five most salient commodification definitions employed across the social sciences, noting that the definition really describes commodification outcomes. Third we propose a definition of commodification whose core idea originated with Marx. Fourth, we note that all of the outcomes described in the most salient definitions of commodification are consistent with the definition of commodification proposed in this paper. Fifth, as a complement to the proposed definition of commodification, we describe the concept of "two spheres" where commodities and relational goods reside to describe the commodification process. In the summary section, this paper claims that distinguishing between the definition of commodification and the outcomes or consequences of commodification eliminates the inconsistency surrounding the term commodification and promotes interdisciplinary communication and cooperation.

\section{Commodities and Relational Goods}

\subsection{What Is a Commodity?}

The term commodity was once widely associated with useful human traits such as the "commodity" of patience. In recent times, there is no longer a consistent definition of what constitutes a commodity. It can mean an economic good, a raw material, an article of commerce, a mass produced and undifferentiated product, or a good that is widely available and has a low profit margin.

Robison and Oliver [4] defined commodities as mostly physical goods and services whose value is associated with their ability to satisfy mostly physical needs. And because they are valued for their mostly physical properties, other goods with the same physical properties are near-perfect substitutes. Further- 
more, because the value of commodities depends on their physical properties, their value is not dependent on who produced, exchanged, consumed, or preserved them. Finally, the value of commodities can be certified by proper inspection and are usually exchanged under similar terms.

\subsection{What Is a Relational Good?}

The concept of a relational good is shared across the social sciences. The nature of relational goods has been discussed by Uhlaner [5], Gui and Sugden [6], Gui and Stanca [7], Becchetti, Pelloni, and Rossetti [8] and Luigino and Stanca [9]. The essence of relational goods is that at least part of their value depends on their connection to people and relationships between people and the social environment in which they are exchanged. There is a socio-emotional component to relational goods because their value derives at least in part from their ability to satisfy socio-emotional needs. Thus, a concise definition of a relational good is one's whose value depends in part on its connections to people. However, there are several relevant characteristics of relational goods that merit elaboration.

\subsection{The Production of Relational Goods}

In mainstream economics, the production of commodities employs manufactured capital (tools and implements), natural capital, human capital, and financial capital. All of these contribute to the creation of a good or service valued for its mostly observable physical properties. In contrast, relational goods are produced in sympathetic, empathetic, trusting, and high regard relationships referred to here and by others as social capital. While there are other definitions of social capital, many of these do not satisfy the requirement of being capital or social. Instead they focus on where social capital lives (networks), what it can produce (cooperation), the rules that organize its use (institutions) and how to produce it [10]. These concepts related to social capital and others, Robison and Flora [11] included in what they referred to as the social capital paradigm.

\subsection{Tangible and Intangible Relational Goods}

Relational goods may be tangible or intangible. Social capital rich exchange partners who empathize, sympathize, trust, and have high regard for others produce intangible relational goods called socio-emotional goods (SEGs), which are capable of satisfying socio-emotional needs. While there is no universally accepted list of socio-emotional needs SEGs are expected to satisfy, generally accepted needs include the need for internal validation or self-actualization, the need for external validation, the need for connectedness (belonging, love and friendship), and the need for knowing [12] [13].

When SEGs become embedded in or associated with commodities and other objects, they create an attachment value for the object in addition to its value connected to its physical properties. The result of embedding objects with SEGs 
is the creation of a relational good referred to as an attachment value good (AVG) that may be tangible or intangible. Though not always called by that name, AVGs are abundant in social life: wedding rings, meaningful songs, family photos, hometowns, artifacts in museums, religious symbols, mementos of emotionally charged experiences, and prized family heirlooms. Because agents produce SEGs and AVGs in social capital rich relationships, SEGs and AVGs are referred to here as relational goods.

\subsection{Exchanges of Commodities and Relational Goods}

Consistent with distinctions between commodities and relational goods are the possibilities of three categories of exchanges: commodities exchanged for other commodities, relational goods exchanged for other relational goods, and exchanges of commodities and relational goods. It is the latter category of exchanges that appears to be at the core of the five salient commodification definitions that are reviewed next.

\section{Five Commodification Definitions and Outcomes}

We now identify at least five distinct definitions of commodification described in the academic literature. These include: (D1) exchanges through which capitalism redefines something in terms of its extrinsic, measurable characteristics [14] [15] [16] [17]; (D2) exchanges that create or enlarge a commodity or consumer culture [18] [19] [20] [21] [22]; (D3) exchanges through which something "human" or "inalienable" becomes valued for its commodity exchange value in a market [23]-[28]; (D4) exchanges through which a product becomes undifferentiated in a market setting [29]; and (D5) neoliberal and globalism exchanges motivated by the economic advantages of international trade [27] [30].

The most pronounced definitional inconsistencies exist between D2 (commodification as an increase in consumer culture) and D4 (commodification as exchanges in which products become undifferentiated). Indeed, the inconsistencies between definitions D2 and D4 have led some to refer to D4 by a variant of the term commodification: "commoditization" [29].

Definitions must take the form $\mathrm{A}$ equals $\mathrm{B}$ where $\mathrm{A}$ and $\mathrm{B}$ are equivalent concepts or things. Technically, D1 through D5 are not definitions but descriptions of alternative outcomes or consequences of converting relational goods into commodities. Definition D1 describes the outcome or consequence of commodification as a shift in the perception one has of another person or object. Definition D2 describes the outcome or consequence of commodification as a cultural shift that alters the view of what is considered an exchange of commodities. Definition D3 describes the outcome or consequence of commodification as when a previously unsalable object being exchanged in a commodity market setting. Definition D4 describes the outcome or consequence of commodification as impersonally produced products without connections to a person(s) replaces goods once valued because of their unique connections to artisans and persona- 
lized production processes. Finally, definition D5 describes the outcome or consequence of commodification as relationships between nations coming to be viewed and valued for their commodity exchange possibilities.

\subsection{Commodification Defined}

We propose that commodification be defined as social exchanges that convert relational goods into commodities. Marx, apparently, had such a commodification definition in mind when he wrote: commodification reduces the relational aspect of an exchange (human interaction) to mere commodity relations [31]. So credit Marx with the commodification definition proposed here. Our task is to demonstrate that the commodification definition proposed by Marx and elaborated here is consistent with the commodification outcomes described in Table 1. In other words, the claim here is that each of the commodification outcomes described in D1 through D5 results from processes in which a relational good whose value previously was determined by its connections to people and places and events involving people, has become valued as a commodity for its observable (physical) properties that are independent of relationships.

\subsection{Importance of Setting}

Before demonstrating that the outcomes described in D1 through D5 are consistent with the commodification definition proposed above, we explain that different human exchange settings can produce different commodification outcomes. Consider how the different settings described in D1 through D5 produce

Table 1. Restates the definitions of and provides examples of commodification outcomes consistent with each definition.

1. Definitions of and examples of outcomes of commodification consistent with each definition of commodification

Definitions
(D1) Exchanges through which capitalism
redefines something in terms of its extrinsic,
measurable characteristics.
Discussion and examples

Exchanges in which the value of relational goods attributed to their connection to a person(s) are ignored and instead goods are valued for their physical properties that can be exchanged in arm's length markets. For example, this process can be observed at estate sales when goods once partially valued for their connections to people are valued only for their physical properties.

Settings in which people view commodity exchanges as increasingly important. Furthermore, as the commodity culture expands, the value of commodities exchanged depends increasingly of their

(D2) Exchanges in which a commodity culture is created or enlarged.

(D3) Exchanges through which something "human" or "inalienable" becomes valued for its exchangeability in a market

(D4) Exchanges through which a product becomes undifferentiated in a market settin

(D5) Neoliberal globalism ideas associated with laissez-faire economics are applied to exchanges in international trading settings physical properties traded in arm's length markets. For example, care of the elderly was once viewed as an exchange of relational goods. Increasingly, the care of the elderly is reduced to an economic exchange of money for services.

Exchanges in which buying/selling something previously deemed "unsalable" because of its relational nature comes to be viewed as a commodity in which its value depends only on its observable (mostly physical) properties. Examples include the sale of body parts, prostitution, and slavery.

Production processes (a type of exchange) and products that once could be associated with a particular skilled artisan are produced in processes in which the product can no longer be identified with a particular individual. For example, violins and some furniture were once produced in cottage

industries by individuals known to the buyers. Now violins and furniture (with some exceptions) are no longer identified with a specific individual.

International trade exchanges in which the products including relational goods are viewed as commodities and exchanged for money which lead countries to value their relationships with other nations in terms of their commodity exchange potential. 
different commodification outcomes consistent with the definition of commodification proposed above.

In D1, the commodification setting is a capitalistic arm's length market in which goods are valued for their observable and mostly physical characteristics where exchanges are motivated by selfish preferences for commodities which convert relational goods into commodities. In D2, the commodification setting is impersonal production processes produces products not identified with persons. In this setting more efficient means of production produce commodities that replace relational goods once produced in cottage and personalized production processes. In D3, the setting is a culture in which persons value efficiency and other commodity considerations over relational characteristics of goods. In this setting, social distances increase to the point that social interaction is largely determined by commodity desired outcomes. Thus people meet more to exchange commodities than to invest in social capital and exchange relational goods. In D4, the setting is one of economic exigencies and opportunities which induce persons to exchange what once they viewed as a relational good for commodities. In this case, the dominant need or perceived need is for commodities and exchanges of relational goods are replaced by commodities. In D5, the setting in international in which weakening interpersonal ties between persons in different countries, reducing their view of each other's country as having value only as potential commodity trading partners. In this setting, the tie between countries and cultures is advantages from commodity exchanges.

\subsection{Commodification as Exchange}

Earlier, we gave a provisional definition of commodification and now recommend that commodification be defined as social exchanges that convert relational goods into commodities. In support of this definition, we note that the outcomes or consequences of commodification described in D1 through D5 are consistent with the notion that the commodification process consists of human exchanges that convert a relational good into a commodity.

(D1) Social exchanges through which capitalism redefines a relational good into something defined by its extrinsic, measurable characteristics. Through capitalism, values of efficiency and market exchange in order to accumulate wealth became more widespread [32]. As noted by Veblen [33], and Adorno and Horkheimer [18] this resulted in an increasing number of objects coming to be regarded in terms of their value in a commodity-oriented system.

In short, things that were once valued as relational goods now take on a new kind of valuation-one that reduces its worth to just a handful of commodity-oriented characteristics (in the fashion of hedonics).

(D2) Social exchanges that creates/enlarges the commodity culture. This outcome refers quite literally to social exchanges that make commodities more importance in people's lives. Consequently, the definition of commodification as converting relational goods into commodities is compatible with this process. 
(D3) Social exchanges through which something "human" or "inalienable" becomes valued for its exchangeability in a market. This commodification outcome describes any number of social exchanges in which relational goods come to be viewed as commodities in the sense that human thoughts, labor or even rights come to be seen as salable. Sandel [34] compiled a list of such commodifying exchanges that includes paying commodities (money) for: a prison cell upgrade; someone to apologize for you behaving badly; the services of an Indian surrogate mother; the right to exceed the posted speed limit; the right to tattoo a casino ad on the forehead of a single mother; the privilege of immigrating into the United States; admission to a prestigious university; a ticket to a congressional hearing; concierge health care; human lab rats for drug trials-payment increases with the riskiness of the drug; blood; human organs; and the right to pollute.

In short, converting a relational good into a commodity, even by degrees, is consistent with exchanges in which previously unsalable (relational) things are valued and exchanged for commodities.

(D4) Social exchanges in which products becoming undifferentiated. This definition has largely not been regarded as commodification exchanges. Furthermore, it is referred to as commoditization rather than commodification. Still, "a product becoming undifferentiated" fits the commodification definition proposed in this paper. To be specific, physically identical commodity objects can be differentiated by imbuing them with socio-emotional goods that transform the commodity into a relational good differentiated by the relationships involved in the transformation. Exchanges that reverse the process and which are sometimes referred to as commoditization are clearing consistent with the notion of commodification exchanges.

To illustrate, advertising efforts are largely intended to associate or embed a generic product with SEGs (positive feelings about one's own image or one's relationships with others, or simply positive feelings about the brand or company). Therefore, a commoditized good is one that has not been imbued with relational goods, or as the common business notion goes, a product that had its relational good component reduced.

(D5) Exchanges that extend neoliberal globalism. Neoliberal globalism is an international level expression that implies putting commodity-orientation over broader humanistic issues - in other words, reducing the place of relational motives in international relations relative to the place of commodity motives.

In the 1970s-1990s, the United States and other countries engaged in a sort of neocolonialism by offering aid to developing countries in exchange for their adopting policies that decreased nonmarket interventions and increased the power of the free market. The efficacy of this policy has been questioned. In Latin America, for example, the 1990s became known as the Lost Decade because of the economic and social consequences of such programs. Relevant to this paper is that even global neoliberalism fits the exchange perspective de- 
scribed in this paper, in effect reducing international relationships to commodity relations-converting relational goods to commodities.

In short, we find that the social exchange definition of commodification (social exchanges that convert relational goods into commodities) is compatible with a variety of commodification outcomes.

\section{Exchanges between Two Spheres}

\subsection{Two Spheres}

Building on Kant, Cohen [35] described where commodities and relational goods reside. He noted that there is a (virtual) sphere of humanity and a (virtual) sphere of everything else. We will refer to the first sphere as the humanistic sphere and the second sphere as the commodity sphere. We find this a useful complement to the commodification definition.

In the one sphere, commodities are produced, consumed, preserved and exchanged. In the second sphere, relational goods are produced, consumed, preserved, and exchanged. The commodification process consists of removing a relational good from the humanistic sphere and relocating it in the commodity sphere.

To illustrate, the commodification of the environment usually means, supplanting the humanistic value of the environment with business interests that reduce its value to its commercial exchange value in an arm's length market. Or we could describe the commodification of the environment as the process of removing environmental goods from the humanity sphere and relocating them in the commodity sphere. In the humanity sphere the environmental goods were valued for their connections to humanity and their ability to provide the setting for social exchanges. In the commodity sphere, the environmental goods were valued for their observable (physical) properties that could be observed and exchanged for goods of equivalent commodity value.

\subsection{Marx and Exchanges between the Two Spheres}

Marx described the role of exchanges in the commodification process. He wrote: "To become a commodity a product [a relational good] must be transferred to another, whom it will serve as a use value [a commodity], by means of an exchange" (in Appadurai, [36]). In the previous quote and elsewhere, Marx appears to recognize the difference between the commodity sphere and the humanity sphere. For example, in referring to the commodification of labor, Marx and Engels noted: "The bourgeoisie has stripped of its halo every occupation hitherto honoured and looked up to with reverent awe" [31] and that "the bourgeoisie has torn away from the family its sentimental veil, and has reduced the family relation into a mere money relation" [31]. In this effort to describe commodification, the focus appears to be on removing a good from the humanity sphere and relocating it in the commodity sphere through a market exchange of the good in question. 


\section{Other Commodification Outcomes and Processes}

\subsection{Cohen's Synthesis}

Cohen [35] attempted to rationalize the different commodification outcomes and consequences through a synthesis of concepts. He argued that one commodification outcome occurs in human exchanges in which all that the buyer receives is a commodity. The commodity is what the buyer pays for and what the buyer receives. But if in the eyes of the seller, the object sold is valued in part because of its connections to persons which are not transferred to the buyer, then commodification has occurred.

To illustrate, suppose a couple over their lifetimes have accumulated objects, which have become embedded with SEGs converting them to AVGs-relational goods. Then assume the couple dies and their objects are sold as commodities in as estate sale and the connection of the goods to the deceased couple is not conveyed. In this case, the relational goods once owned by the deceased couple have been commodified.

Cohen also referenced Marx's notion that commodification has occurred is an object's value can be captured in a single measure (or set of measures). A related notion in economics is hedonics, in which the assertion is made that the price of an object is determined by a certain set of observable characteristics. This index is, of course, more easily formed if the properties of the good that give rise to the good's value are tangible and observable, the hallmarks of a commodity.

\subsection{Commodification through Destination and Metamorphosis}

In another attempt to rationalize the description of commodification outcomes and processes, Maquette made a distinction between two types of commodification processes. He called one type, commodification by destination and the latter type he called commodification by metamorphosis (in Appadurai [36]). Maquette described commodification by destination as the process through which something is commodified through a physical exchange and commodification by metamorphosis as the process in which the regard for an object is changed.

For example, buying a person could be thought of as commodification by destination while someone that is treated like an object to be used for gain might be thought of as commodification even if no market exchange has taken place.

We interpret Maquette's view of commodification by destination and metamorphosis to mean that commodification can take place through a physical exchange of goods. Alternatively, and at other times, commodification can occur through changes in persons' regard for the object (often by changing the nature of a relationship). To illustrate, think of two examples that could be said to commodify an engagement ring. Suppose a disagreement between an engaged couple loses their affections for each other and destroys the engagement ring's attachment value-or in Marquette's view, commodifies the ring through metamorphosis.

Next suppose, that financial exigencies lead the owner of an engagement ring 
to a pawn shop where the ring is exchanged for an amount of money much less than the ring's value to its owner. In this case, commodification has occurred through destination. Both commodification by metamorphosis and commodification by destination would be viewed as exchanges and both processes can be said to commodify something.

Maquette's commodification by destination definition can be used to describe the commodification that occurred during the industrial revolution. Veblen [33], Lukács [37], Adorno \& Horkheimer [18], Polanyi [38] and others (largely associated with the Frankfurt school) noted that, as a result of the industrial revolution, everything included in one social life (including relationships) could be produced, bought, packaged up and sold for a price that depended on some easily identifiable external characteristics.

In more recent times, commodification by metamorphosis has been used to describe the way society and consumerism act upon and transform each other in a way that commodify objects and people [39] [40] [41]. For example, there was a time when childcare in the United States was largely a relational good provided by (mostly) the mother to the child. Then as views about work and the home changed, childcare was converted from being viewed as a relational good to a commodity [42]. In short, a change in the way people interacted gave rise to social changes especially in the nature of relationships and a change in the way all aspects of social life came to be seen.

Finally, reconsider Marquette's notions of commodification by destination or by metamorphosis in the context of exchanges between two spheres. If an object is a relational good and resides in the humanity sphere and commodification by destination or metamorphosis occurs, then the relational good has become a commodity and commodification has occurred. Or using the framework of the two spheres, either through commodification by destination or by metamorphosis, relational goods are removed from the humanity sphere and relocated in the commodity sphere.

However, there are a two other issues that should be addressed in order to facilitate interdisciplinary collaboration and communication around the concept of commodification. These are 1) issues of perspective, ex ante and ex post, in commodification studies, and 2) the elaboration of the concept of decommodification in a way that is consistent with the concept of commodification as has been defined in this paper.

\section{Ex-Ante and Ex-post Commodification}

One strength of the commodification definition proposed in this paper is that it can consider multiple types of exchange that convert a relational good into a commodity. However, within the social science disciplines there appear to be some sort of competition to label some commodification outcomes as good and others bad.

For example, some social advocates suggest that businesses often harm society 
through commodification. Businesses, in contrast, go to some effort to convert commodities into relational goods which is the opposite of commodification according to our definition. One might ask, "Which side is correct?" The social exchange perspective illustrates that they both are-under certain conditions. Businesses stand to gain more by converting their commodities into relational goods in the eyes of their customers, but in so doing, they commodify relationships. This is because businesses often imbue their otherwise generic products with ex ante notions about relationships derived from their product-having more friends, fitting in with certain people or "getting the girl". While this does increase the relational content of the product for some and may provide enhanced customer experiences, it does so at the expense of relationships coming to be seen as something that can be bought in association with a commodity. In short, there is a sort of quid pro quo of commodification in which decommodifying $\mathrm{X}$ by associating it with $\mathrm{Y}$ often commodifies $\mathrm{Y}$ in the process.

\section{Decommodification}

Logically it seems that decommodification should be seen as the opposite of commodification. However, this is not how decommodification has been viewed in the literature. Instead, decommodification is widely regarded as state power exerted over market power-providing welfare and other public services that people need to survive [43]. This view of decommodification, however, represents only one aspect of decommodification. We describe next an alternative view of decommodification that is consistent with the definition of commodification proposed in this paper.

This study proposes that to be consistent with the social exchange perspective of commodification and the commodification definition proposed in this paper, that decommodification be defined as social exchanges that convert commodities into relational goods, in effect removing them from the commodity sphere and relocating them in the humanistic sphere. Decommodification outcomes and consequences might include: valuing objects for their connections to people rather than valuing them for their exchange value as commodities in arm's length markets; decreasing the commodity culture; making something common and exchanged in arm's length markets- "off limits" or not for sale (as was the case with human organs in the United States in the 1980s); humanizing products by adopting production processes that associate people with the production of a good; or adopting exchange programs that establish social capital ties between persons in different countries or cultures.

This study also proposes that social exchanges consistent with the view of decommodification proposed here has a host of academic applications. Decommodification might be a new lens through which studies of indigenous and human rights, altruism, environmentally sustainable business practices could be examined. These applications (and others) would greatly expand the current usage of the term which has almost come to be coopted by notions of state interven- 
tion.

\section{Conclusions}

To rationalize inconsistencies in the most salient commodification definitions is an ambitious goal. However, this paper suggests that such a goal can be achieved by elaborating the social exchange perspective to include relational goods. To elaborate the social exchange perspective by including relational goods allows us to define commodification as the conversion of a relational good into a commodity through different social exchanges processes including metamorphosis or by destination. Converting a relational good into a commodity, commodification, can be viewed as a process in which a good from a humanity sphere is relocated in the commodity sphere where instead of being valued for its connections to persons that enable it to satisfy important socio-emotional needs, it is valued for its physical properties that satisfy mostly physical needs. This view of commodification is consistent with the major notions of commodification outcomes and honors, the views of Marx who may be viewed as the leader in defining and emphasizing the definition and outcomes of commodification.

In addition, the definition of commodification proposed in this paper makes it evident that commodification and decommodification can be seen more as two opposing types of exchanges, challenging the notion that decommodification is largely synonymous with provision of state welfare.

Finally, we note that the proposed commodification and decommodification definitions have many applications for research in such areas as religious studies, altruism, environment and conservation, human rights and non-capitalist cultures.

If the social sciences do not agree on the commodification definition, confusion will result and limit accurate communication and cooperation. The purpose of this paper has been to provide a commodification definition consistent with a wide variety of commodification outcomes described in the various social science literatures. Hopefully, having proposed such a definition will facilitate interdisciplinary collaboration and accurate communication about a wide variety of commodification outcomes.

\section{References}

[1] Homans, G.C. (1958) Social Behavior as Exchange. American Journal of Sociology, 63, 597-606. https://doi.org/10.1086/222355

[2] Blau, P.M. (1964) Exchange and Power in Social Life. Transaction Publishers, Piscataway.

[3] Emerson, R. (1976) Social Exchange Theory. Annual Review of Sociology, 2, 335-362. https://doi.org/10.1146/annurev.so.02.080176.002003

[4] Robison, L.J. and Oliver, J.R. (2016) Explaining Economic Anomalies through Relational Goods. Unpublished Manuscript Presented at the Annual Agricultural and Applied Economics Meeting, Boston, 33.

[5] Uhlaner, C.J. (1989) Relational Goods and Participation: Incorporating Sociability 
into a Theory of Rational Action. Public Choice, 62, 253-285.

https://doi.org/10.1007/BF02337745

[6] Gui, B. and Sugden, R., Eds. (2005) Economics and Social Interaction: Accounting for Interpersonal Relations. Cambridge University Press, Cambridge.

[7] Gui, B. and Stanca, L. (2010) Happiness and Relational Goods: Well-Being and Interpersonal Relations in the Economic Sphere. International Review of Economics, 57, 105-118. https://doi.org/10.1007/s12232-010-0099-0

[8] Becchetti, L.A.P. and Rossetti, F. (2008) Relation Goods, Sociability, and Happiness. Center for Economic and International Studies, 6, 1-27.

[9] Luigino, B. and Stanca, L. (2008) Watching Alone: Relational Goods, Television and Happiness. Journal of Economic and Behavioral Organization, 65, 506-528. https://doi.org/10.1016/j.jebo.2005.12.005

[10] Robison, L.J., Schmid, A.A. and Siles, M.E. (2002) Is Social Capital Really Capital? Review of Social Economy, 60, 1-21.

[11] Robison, L.J. and Flora, J.L. (2003) The Social Capital Paradigm: Bridging Across Disciplines. American Journal of Agricultural Economics, 85, 1187-1193. https://doi.org/10.1111/j.0092-5853.2003.00528.x

[12] Maslow, A.H. (1943) A Theory of Human Motivation. Psychological Review, 50, 370-396. https://doi.org/10.1037/h0054346

[13] Lieberman, M.D. (2013) Social: Why Our Brains Are Wired to Connect. Crowne Publishers, New York.

[14] King, D.A. and Stewart, W.P. (1996) Ecotourism and Commodification: Protecting People and Places. Biodiversity \& Conservation, 5, 293-305. https://doi.org/10.1007/BF00051775

[15] Halewood, C. and Hannam, K. (2001) Viking Heritage Tourism: Authenticity and Commodification. Annals of Tourism Research, 28, 565-580. https://doi.org/10.1016/S0160-7383(00)00076-1

[16] Suddaby, R. and Greenwood, R. (2001) Colonizing Knowledge: Commodification as a Dynamic of Jurisdictional Expansion in Professional Service Firms. Human Relations, 54, 933-953. https://doi.org/10.1177/0018726701547007

[17] Heller, M. (2003) Globalization, the New Economy, and the Commodification of Language and Identity. Journal of Sociolinguistics, 7, 473-492. https://doi.org/10.1111/j.1467-9841.2003.00238.x

[18] Adorno, T.W. and Horkheimer, M. (1972) Dialectic of Enlightenment. John Cumming (trans), Herder, New York.

[19] Burke, T. (1996) Lifebuoy Men, Lux Women: Commodification, Consumption, and Cleanliness in Modern Zimbabwe. Duke University Press, Durham.

[20] Loader, I. (1999) Consumer Culture and the Commodification of Policing and Security. Sociology, 33, 373-392. https://doi.org/10.1177/S003803859900022X

[21] Cook, D.T. (2004) The Commodification of Childhood: The Children's Clothing Industry and the Rise of the Child Consumer. Duke University Press, Durham.

[22] Thrift, N. (2006) Re-Inventing Invention: New Tendencies in Capitalist Commodification. Economy and Society, 35, 279-306. https://doi.org/10.1080/03085140600635755

[23] Willmott, H. (1995) Managing the Academics: Commodification and Control in the Development of University Education in the UK. Human Relations, 48, 993-1027. https://doi.org/10.1177/001872679504800902 
[24] Goulding, C. (2000) The Commodification of the Past, Postmodern Pastiche, and the Search for Authentic Experiences at Contemporary Heritage Attractions. European Journal of Marketing, 34, 835-853. https://doi.org/10.1108/03090560010331298

[25] Salzman, J. and Ruhl, J.B. (2000) Currencies and the Commodification of Environmental Law. Stanford Law Review, 53, 607-694. https://doi.org/10.2307/1229470

[26] Lawrence, S. and Sharma, U. (2002) Commodification of Education and Academic Labour-Using the Balanced Scorecard in a University Setting. Critical Perspectives on Accounting, 13, 661-677. https://doi.org/10.1006/cpac.2002.0562

[27] Liverman, D. (2004) Who Governs, at What Scale and at What Price? Geography, Environmental Governance, and the Commodification of Nature. Annals of the Association of American Geographers, 94, 734-738.

[28] Cole, S. (2007) Beyond Authenticity and Commodification. Annals of Tourism Research, 34, 943-960. https://doi.org/10.1016/j.annals.2007.05.004

[29] Rushkoff, D. (2005) Commodified vs. Commoditized. http://www.rushkoff.com/blog/2005/9/4/commodifiedvscommoditized.html

[30] Cameron, D. (2000) Styling the Worker: Gender and the Commodification of Language in the Globalized Service Economy. Journal of Sociolinguistics, 4, 323-347. https://doi.org/10.1111/1467-9481.00119

[31] Marx, K. (2000) Karl Marx: Selected Writings. Oxford University Press, Oxford.

[32] Weber, M. and Kalberg, S. (2009) The Protestant Ethic and the Spirit of Capitalism, with Other Writings on the Rise of the West. Oxford University Press, Oxford.

[33] Veblen, T. (1965 [1899]) The Theory of the Leisure Class. AM Kelley, Bookseller.

[34] Sandel, M.J. (2012) What Money Can't Buy: The Moral Limits of Markets. Macmillan, Basingstoke.

[35] Cohen, I.G. (2003) The Price of Everything, the Value of Nothing: Reframing the Commodification Debate. Harvard Law Review, 117, 689-710. https://doi.org/10.2307/3651950

[36] Appadurai, A. (1988) The Social Life of Things: Commodities in Cultural Perspective. Cambridge University Press, Cambridge.

[37] Lukács, G. (2010) Reification and the Consciousness of the Proletariat. In: Szeman, I. and Kaposy, T., Eds., Cultural Theory: An Anthology, Wiley-Blackwell, West Sussex, 172-187

[38] Polanyi, K. (1944) The Great Transformation: The Political and Economic Origins of Our Time. Beacon Press, Boston.

[39] Baudrillard, J., Lovitt, C.R. and Klopsch, D. (1976) Toward a Critique of the Political Economy of the Sign. SubStance, 5, 111-116. https://doi.org/10.2307/3684064

[40] Chomsky, N. (1999) Profit over People: Neoliberalism and Global Order. Seven Stories Press, New York.

[41] Gottdiener, M., Ed. (2000) New Forms of Consumption: Consumers, Culture, and Commodification. Rowman \& Littlefield, Lanham.

[42] Ungerson, C. (1997) Social Politics and the Commodification of Care. Social Politics, 4, 362-381. https://doi.org/10.1093/sp/4.3.362

[43] Esping-Andersen, G. (1988) Decommodification and Work Absence in the Welfare State. International Journal of Sociology, 21, 77-111.

https://doi.org/10.1080/15579336.1991.11770014 